\title{
A Simple Economics in Local Hospital Information Management
}

\author{
LIN Xixi ${ }^{\text {a,* }}$ \\ ${ }^{a}$ Department of public economics, Xiamen University, Xiamen, China
}

\begin{abstract}
Can the rural people benefit from New Cooperative Medical Scheme? We set up a simple economic model to show that the rural patient can benefit from NCMS under a good supervision system which depends on the hospital information management. Based on the theoretical model, we give some suggestions for the current local hospital information management.
\end{abstract}

Index Terms: New Cooperative Medical Scheme; Moral Hazard; Local Hospital Information Management

(C) 2011 Published by MECS Publisher. Selection and/or peer review under responsibility of the Research Association of Modern Education and Computer Science.

\section{Introduction}

China has witnessed a fast growth since the Reform and Open Policy in 1978. However, there are some problems in growing China; one of them is the poverty. Illness has emerged as major cause of poverty in rural China [2]. How to make people in the rural region rich and live a good life is an important task for the government. The poor in rural region cannot afford the medical service and become unhealthy [7]. This has caused great concerns. The New Cooperative Medical Scheme (NCMS hereafter) was implemented in 2006 and aimed to help the rural patient having the right to see a doctor and being healthy. People in countryside just pay for 10 Yuan each year as health insurance, and then most of their expenses in hospital can be paid by the government in the end. The rural patient hesitates about seeing a doctor and local hospital in small towns is run with difficulty due to the lack of the patient who cannot reveal his demand for medical service because of low income before NCMS. Things have changed since 2006. By investigating related people in 8 counties (cities), Cheng et al (2010) find the hospitalization ratio increases while medical expenses rises in local medical hospital in small towns which is shown in table 1 . They also find the local hospital in small towns has a tendency of making a profit since 2006 [3]. As a result, the local hospital in small towns benefits from NCMS with a rise of rural patients. Does the rural patient benefit from NCMS? This question needs to be answered to give some useful suggestions for NCMS in progress.

As we know, the doctor has more information on the disease than the patient with his special medical knowledge and skills, and this asymmetric information structure will result in a moral hazard problem [5]. This problem may exacerbate because most of the rural patients receive a few education. The agent will cheat if the

* Corresponding author:

E-mail address: linxixi@xmu.edu.cn 
government can monitor with imperfective information [1]. Thus the doctor may have the incentive to cheat the patient even in case of the supervision of the government. In practice, when the patient comes to see a doctor, he has to accept the bill from the doctor. To make the problem clear, we set up principle-agent economy model, based on which, we find local hospital information management is of importance to decide whether the patient benefits from it or not.

Table 1. Hospitalization In Local Hospital Around 2006

\begin{tabular}{|c|c|c|c|c|c|c|}
\hline \multirow{2}{*}{ county } & \multicolumn{2}{|c|}{ Hospitalization ratio } & \multicolumn{2}{|c|}{ Hospitalization days } & \multicolumn{2}{|c|}{ Hospitalization expense } \\
\hline & 2005 & 2007 & 2005 & 2007 & 2005 & 2007 \\
\hline $\mathrm{A}$ & 5.98 & 6.48 & 2.25 & 3.93 & 505.07 & 592.63 \\
\hline B & 3.1 & 2.42 & 4.28 & 4.43 & 269.78 & 365.08 \\
\hline $\mathrm{C}$ & 2.33 & 2.97 & 6.25 & 6.34 & 665.22 & 969.76 \\
\hline $\mathrm{D}$ & 4.09 & 4.78 & 3.23 & 3.52 & 304.77 & 277.34 \\
\hline E & 1.3 & 2.37 & 5.80 & 3.90 & 179.13 & 174.13 \\
\hline $\mathrm{F}$ & 4.96 & 6.32 & 2.91 & 2.85 & 270.57 & 686.67 \\
\hline$G$ & 1.93 & 4.83 & 8.75 & 8.32 & 350.74 & 489.78 \\
\hline $\mathrm{H}$ & 0.81 & 1.23 & 7.30 & 8.1 & 230.02 & 377.32 \\
\hline
\end{tabular}

We set up a theoretical model in section II, and conclude that the patient may suffer a loss from NCMS to show the importance of local hospital information management. Then we make a brief introduction of the problem in current local hospital information management and give some suggestions based on the theoretical model in section III. Section IV concludes the main result.

\section{The Model}

\subsection{Setup}

There are three agents in the economy: a continuum of patient with measure one, a doctorand the government. The patient from countryside has to decide whether to see a doctor, however, the medical expenses are of uncertainty: $M_{h}$ with probability 1-p, $M_{l}$ with probability $p, M_{h}>M_{l}$. The distribution of uncertainty is known by all the agents. We assume that a representative patient's reserved utility is negative to the expenses so that he will see a doctor if the expected a medical expense is less than $\mathbf{M}_{0}$.

Then the doctor who has the private information on the medical expense knows the actual medical expense and he can cheat the patient with probability $\mathrm{q}$ when he finds the real expense is low and tell the patient that her medical expenses are $\mathbf{M}_{\mathrm{h}}$. However, the patient who goes to see a doctor has no choice but to accept it. The medical cost of high expenses and low expenses for the doctor are $C_{h}$ and $C_{l}$ respectively. We assume that $M_{h}$ $\mathrm{C}_{\mathrm{h}}>\mathrm{M}_{1}-\mathrm{C}_{\mathrm{l}}$ which is consistent with the practical medical fact and the doctor has the incentive to cheat.

However, the government can only imperfectly monitor the doctor on the average medical expenses the rural patient pay to the doctor. She can observe the cheating of the doctor with probability (q) and punish the doctor with $\left(\mathrm{M}_{\mathrm{h}}-\mathrm{M}_{\mathrm{l}}\right)$. It is natural that cheating of the doctor is found more easily when he cheats more so that (q) increases with $\mathrm{q}$, that is

$$
(\mathrm{q})=\mathrm{q},>1
$$

Where,shows ability of the government to find cheating of the doctor which depends on local hospital information management required by the government. Good local hospital information management results in good ability to observe the cheating. The higher, the more heavy punishment to the doctor. 
Therefore, the doctor's expected payoff is

$$
(q)=p(1-q)\left(M_{1}-C_{l}\right)+(1-p+p q) *\left(M_{h}-C_{h}\right)-p q^{2}\left(M_{h}-C_{h}\right)
$$

if the patient goes to see a doctor. Otherwise the payoff would be zero.

Then we will get the best choice of cheating $\mathrm{q}$

$$
\mathrm{q}^{*}=\left[\left(\mathrm{M}_{\mathrm{h}}-\mathrm{C}_{\mathrm{h}}\right)-\left(\mathrm{M}_{\mathrm{l}}-\mathrm{C}_{\mathrm{l}}\right)\right] /\left[2\left(\mathrm{M}_{\mathrm{h}}-\mathrm{M}_{\mathrm{l}}\right)\right]
$$

The numerator of (2) shows the incentive of cheating while the denominator denotes the actual punishment received from the government. Intuitively, the doctor will be more likely to cheat in the case of higher incentive or lower actual punishment from (2).

At this time, the payoff of the doctor is

$$
=\left[p\left(M_{1}-C_{l}\right)+(1-p)^{*}\left(M_{h}-C_{h}\right)\right]+p\left[\left(M_{h}-C_{h}\right)-\left(M_{1}-C_{l}\right)\right] /\left[4\left(M_{h}-M_{l}\right)\right]
$$

The second term of (3) denotes the benefit from cheating of the doctor. With a higher punishment, a higher observing ability and low cheating incentive, the benefit will be lower. What's more, the rural patient gets loss

$\mathrm{p}$, if he can go to see a doctor.

$$
\mathrm{p}=\mathrm{p}\left[\left(\mathrm{M}_{\mathrm{h}}-\mathrm{C}_{\mathrm{h}}\right)-\left(\mathrm{M}_{1}-\mathrm{C}_{\mathrm{l}}\right)\right] /(2)
$$

\subsection{Transfer in NCMS}

To clarify the idea, we assume that the ex ante expected expenses goes beyond $\mathrm{M}_{0}$ so that no patient would see a doctor and the doctor will get zero payoff. This is similar with the local rural fact before NCMS. When NCMS is implemented, the patient in the countryside receives transfer from the government so that she can change her mind and see a doctor.

Then the doctor chooses the optimal cheating probability as showed in (2) and gets her most profit. The doctor benefits from the program.

What about the patient? We turn to the ex-post expected payoff received by the patient. We use negative term of expenses to declare the payoff.

$$
\mathrm{p}^{\mathrm{ep}}=\left[-\mathrm{pM}_{\mathrm{l}}-(1-\mathrm{p})^{*} \mathrm{M}_{\mathrm{h}}\right]-\mathrm{p}\left[\left(\mathrm{M}_{\mathrm{h}}-\mathrm{C}_{\mathrm{h}}\right)-\left(\mathrm{M}_{\mathrm{l}}-\mathrm{C}_{\mathrm{l}}\right)\right] /(2)
$$

The first bracket in (4) shows ex ante expected payoff while the next one denotes loss caused by the cheating.

So far as participation constraint is concerned

$$
\text { . }+\mathrm{M}_{0}-\mathrm{pM}_{1}-(1-\mathrm{p})^{*} \mathrm{M}_{\mathrm{h}}>0
$$

Therefore, based on (4) and (5), the patient will benefit from NCMS if

$$
\mathrm{p}\left[\left(\mathrm{M}_{\mathrm{h}}-\mathrm{C}_{\mathrm{h}}\right)-\left(\mathrm{M}_{1}-\mathrm{C}_{\mathrm{l}}\right)\right] /(2)<+\mathrm{M}_{0}-\mathrm{pM}_{1}-(1-\mathrm{p})^{*} \mathrm{M}_{\mathrm{h}}
$$

Which means that with a higher transfer and a higher actual punishment rate, the patient can benefit from NCMS.

We introduce transfer to simplify the analysis, the transfer turns out to be subsidies from central government and local government. The central government gave its subsidies for enrollees in the central and western 
provinces to 20 Yuan and required local governments to give their subsidies 10 Yuan as well in 2006, and this subsidy increased to 80 Yuan with 40 Yuan from central government in 2008. The rural patient may effectively benefit from the policy due to rise of transfer in the model.

On the other side, the patient may suffer a loss from NCMS if cheating incentive is large enough or actual punishment rate is low enough. What's more, a higher $\mathrm{p}$ results in loss to the patient. We can get this intuition: the patient suffers loss when his medical expense is low since the doctor can cheat only at that case. A higher $p$ implies lower medical expenses, then he will be cheated more and suffer greater loss.

Therefore, with transfer given by the government, the doctor can benefit from it while the patient, who is the government aims to help most, may suffer a loss as a result due to the cheating of the doctor.

However, the government may have with some difficulty in increasing the punishment for the sake of law system. Thus another way for the government is to improve the supervision ability. It is reasonable to turn to the investment of local hospital information management.

\subsection{Investment in local hospital information management}

Local hospital information management is a platform that deals with medical process including offering medical service, applying for reimbursement of medical expenses and feedback from the patient by computer network. The government can monitor the doctor efficiently if it runs well. In general, the supervision ability gets improved as the investment on it increases.c where denotes the investment by the government. So the government faces a tradeoff between transfer and investment on local hospital information management given total expenses on NCMS.

$$
=16 \mathrm{c}^{2} /\left\{\mathrm{p}^{2}\left[\left(\mathrm{M}_{\mathrm{h}}-\mathrm{C}_{\mathrm{h}}\right)-\left(\mathrm{M}_{1}-\mathrm{C}_{1}\right)\right]^{2}\right\}
$$

We find the optimal investment is independent of total expenses because the marginal benefit of transfer is constant with 1 .

\section{Policy Suggestion}

We argue that the patient in rural region may suffer a loss from NCMS based on principal-agent model. Some empirical findings support this argument. Lei and Lin (2009) empirically show that they don't find NCMS increases utilization of formal medical service or improves health status measured by self-reported health status and by sickness or injury in the past four weeks. What's more, they don't find that NCMS increases the expenses of the patient [4]. Poor local hospital information management should be the main excuse for this, for the government should find the cheating of the doctor more easily with good system which implies the increase of $\pi$.

In this section, therefore, we make a brief introduction of the problems that lie in local hospital information system, then we put forward some suggestions to settle the problems.

\subsection{Problem in Local Hospital Information Management}

1) The government doesnot realize the importance of information management. Just thinks if he can set aside more money to the rural patient, she will be able to pay for her disease and benefit from the NCMS, so the information management is of no importance [6]. The government doesnot realize the role of information management in supervision system which can actually make the NCMS takes its effect to let the rural patient benefit from it.

2) The local hospital is short of money in information construction. Many local hospitals didn't manage well and suffered a loss before, so it couldn't set aside too much money to information construction. What's 
more, as discussed above, good information management prevents him from cheating, which shows that he has too much incentive to do this.

3) The current information software results in a lot of complaints. Hospital software has been developed and come into use in some rich local hospital. However, it turned out with disappoint. The doctor didn't know how to use it while the government couldn't get more information from it. The developers of the software should be responsible for it because they have inadequate medical knowledge.

4) The patient cannot access the information system. Without good hospital information system, the rural patient has no idea on his illness, so he gets a disadvantage position on the medical service. On the other side, there are few feedback tunnels in the information system so that the government hardly gets the complaint form the patient. All these may result in cheating from the doctor with high probability.

As a result, the current local hospital information management contains in a lot of problem, and the government cannot perform his function of supervision very well, which may result in the loss of the rural patient under the NCMS. Thus we put forward some suggestions for it so that the rural patient can benefit from the NCMS.

\subsection{Some Suggestions}

1) The governemt should invest some fund in the construction of local hospital information. The government should recognise that the information system plays an important role in its supervision syestem, and set aside some fund to invest the construction of information. At the same time, the government should declare that the local hospital should be reponsible for offering evidences in case of the dispute of medical accidents. With this, the local hospital has some incentive to invest in information management.

2) A good local information software system should be developed. A lot people besides the computer egineer will be invovled in this work. With his professional knowledge, the doctor should be invited into the design of information so that the system can meet his need in medical service. The manager of supervision should communicate with the design more often so that the system can perform its function well when it comes into use. Besides, any the oringal data should not be modified by the hospital.

3) The government should set up information disclosure and feedback system to the patient. The information of illness, with its symptom, the treatment and expenses at each local hospital should be known by the rural patient so that he can decide effectively if he was cheated by the doctor. The patient who gets the transfer from the government and goes to see a doctor should be invited to report his medical information. The government should give her some response to the information.

\section{Conclusion}

Focusing on whether the patient benefits from the NCMS or not, we set up an economic model to show the supervision is important. Good information management results in strong supervision and government should be responsible for it. Based on this, we suggest that the government should invest some funding in the local hospital information construction, develop good local information software and set up information disclosure and feedback system to improve the information management so that the rural patient can benefit from NCMS.

\section{Acknowledgements}

This paper is supported by National Nature Science Fund, the program number is 7080341. 


\section{References}

[1] Michael G. Allingham and Agnar Sandmo, "Income tax evasion: a theoretical analysis", Journal of Public Economics, Vol 1, 1972, pp.323-338.

[2] Phlip H. Brown and Caroline Theoharides, "Health-seeking behavior and hospital choice in China's new cooperative medical system", Health Economics, Vol 18, 2009, pp.47-64

[3] Cheng Bin, Ren Gang, Wang Zao-li, Yang Zhi-yong and Zhang Xi-fan, "The influencing factors of average hospitalization expenses in contracted health facilities in New Rural Cooperative Medical Scheme", Chinese Health Economics, Vol 11, 2010, pp.45-47.(in Chinese)

[4] Xiaoyan Lei and Wanchuan Lin, "The New Cooperative Medical Scheme in rural China : does more coverage mean more service and better health?", Health Economics, Vol 18, 2009, pp.25-46.

[5] Zijian Xia, "Moral hazard and its elusion in the New Rural Cooperative Medical System: investigation in Longhui County of Hunan Province", Journal of Wuhan University of Technology(Social Science Edition), Vol 20, 2007, pp.755-758. (in Chinese)

[6] Yang Zhi-yong, Fu Xiao-guang, Wang Zao-li, "The current situation and problems in constructing the new Rural Cooperative Medical Scheme Information System”, Chinese Health Economics, Vol 28, 2009, pp. 41-42. (in Chinese)

[7] Hongmei Yi, Linxiu Zhang, Kim Singer, Scott Rozelle and Scott Atlas, "Health insurance and catastrophic illness: a report on the new cooperative medical system in rural China", Health Economics, Vol 18, 2009, pp.119-127. 